\title{
Hernández, R., Marrugo, L, Henry, A., Delgado, R., Vanegas, D., Morales, E., Daza, S., Muñoz, E., y Gavalo, G. (2019). Saberes ancestrales, soberanía alimentaria en sus diversas formas afrodescendientes y palenqueras. Cartagena: Instituto de educación e investigación "Manuel Zapata Olivella" [176 pp]
}

Rubén Hernández Cassiani

Instituto de Educación e Investigación Manuel Zapata Olivella-Colombia, rubenhernandezca@hotmail.com

acceso $\odot$ abierto

Cómo citar: Hernandez, R. (2020). Hernández, R., Marrugo, L, Henry, A., Delgado, R., Vanegas, D., Morales, E., Daza, S., Muñoz, E., y Gavalo, G. (2019). Saberes ancestrales, soberanía alimentaria en sus diversas formas afrodescendientes y palenqueras. Cartagena: Instituto de educación e investigación "Manuel Zapata Olivella" [176 pp]. Palobra, 20(1), 113-125.

https://doi.org/10.32997/2346-2884-vol.20num.1-2020-3229

Recibido: 24 de marzo de 2020.

Aprobado: 27 de mayo de 2020.

Editora: Rosario Blanco Bello. Universidad de Cartagena-Colombia.

Tipología IBN Publindex:

Reseña Bibliográfica.
Copyright: (C) 2020. Hernández, R. Este es un artículo de acceso abierto, distribuido bajo los términos de la licencia https://creativecommons.org/licenses/by-ncsa/4.0/ la cual permite el uso sin restricciones, distribución y reproducción en cualquier medio, siempre y cuando que el original, el autor y la fuente sean acreditados.

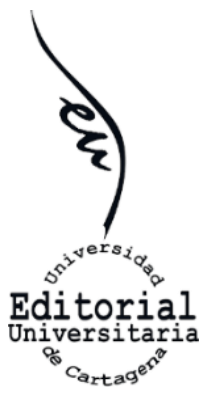

"Entonces nos contó muchas historias de nuestros antepasados y Orishas que él sabe ligar unas a otras. Dice que no hemos nacido esclavos y que descendemos de la más antigua raíz del Muntu; que en el pasado nuestros padres sembraron el ñame, el plátano, el coco, el millo y otras plantas que les permiten grandes villas. Con el tiempo, soberanos sabios y poderosos nos dieron leyes, organizan el comercio y sus protegidos artesanos aprenden a labrar el oro y fundir el cobre, el hierro y el bronce. Nos asegura que el Muntu ya había construido grandes ciudades y palacios con abundancia de alimentos y oro a donde llegaron los bárbaros con sus ejércitos y fusiles a matarnos y encadenarnos. Que todos los que mueran combatiendo el yugo del amo serán glorificados por los Orishas y ancestros pero que ninguno regresaría al país natal porque la tierra del exilio debía ser conquistada por los vivos y difuntos para compartirla con los animales, los árboles y nuestros descendientes" (Manuel Zapata Olivella, Changó el gran putas, 1983, p. 150).

El libro publicado en octubre de 2019, cuyos editores son Jesús Natividad Pérez y Rubén Darío Hernández Cassiani y El Instituto de Educación e Investigación Manuel Zapata Olivella, como sello editorial, analiza la producción de alimentos como saber ancestral que integra la soberanía alimentaria de la población palenquera, afrocolombiana, negra y raizal, sin perder de vista los impactos que recibe del capitalismo globalizante y las políticas públicas que implementan.

El libro enseña que la racionalidad palenquera y los saberes alimentarios que sustentan, son las razones que explican la exquisitez o toque singular y sin igual de la cocina afrocolombiana y específicamente palenquera, recogida en sus múltiples recetas presentes en la cocción del bleo, la variedad de pescados y carnes, sobre todo la carne de montes y de los animales domésticos, en la manipulación de alimentos con productos agrícolas como el maíz, la yuca, el ñame, plátano, batata, auyama, papa, aguacate, coco y sus saborizantes o especias como: calabaza, ají, achiote, limón, berenjena, jengibre, orégano, tomate, cebolla, pimentón, pepino, yerbabuena, albahaca, laurel, espinaca, culantro, cilantro, cebollín, ajo, pimentón, vinagre natural, el picante natural basado en coco, cebolla, aceites naturales y demás que están presentes en el arroz con coco, arroz con frijolito, arroz subido, arroz de aceite y auyama, la 
variedad de sancocho, los platos de yuca con chicharrón o chicharrón con patacón.

Las mujeres son quienes más íntegramente, interiorizan y expresan esta sabiduría, ya que tienen mayor paciencia y sentido estético para comunicar y convertir en un acto pedagógico-epistemológico este proceso. De modo que, actúan como el más importante y significativo sujeto epistémico en un lugar o espacio determinado, cuya función epistémica articuladora configura uno de los actos de vida necesarios e imprescindible para garantizar la existencia. La cocina resignifica el lugar como espacio o territorio para la integración, encuentro y diálogo y, por consiguiente, de ruptura con la fragmentación y divisoria platónica-aristotélica que construyó un imaginario despectivo y peyorativo de esta, lo mismo que el positivismo y los compartimentos que concibe la separación de los conocimientos naturales y sociales.

También dice que corresponde a todos aquellos que, desde distintos ángulos y direcciones de su quehacer científico, realizan permanentemente los balances necesarios y sopesan los desafíos que presenta las realidades complejas y cambiantes de los territorios ancestrales, el país y el mundo, para seguir sembrando las semillas florecientes de la tonificación científica natural y social de esta sabiduría ancestral.

La urgencia es apremiante, si tenemos en cuenta el contexto mundial propio del capitalismo global en el que se está inmerso, y el conjunto de situaciones complejas que impactan el mundo identitario de las colectividades étnicas y colectividades sociales poniendo en riesgo y amenazando permanentemente su mundo cultural y la conservación de sus saberes ancestrales.

Los forjadores del paradigma común, en particular Herrero (2012) permanentemente recuerda que:

El sistema productivo actual vive de espaldas a los principios de la termodinámica y constituye más bien un verdadero acelerador entrópico. Consume cantidades ingentes de energía fósil de baja entropía que ya nunca más estará disponible, "desordena" las complejas estructuras de los suelos y de los ecosistemas destruyendo la arquitectura natural que asegura la reproducción de la vida; simplifica las cadenas tróficas que aseguran el fluyo de la energía solar antes de que se pierda irremediablemente por disipación; rompe los grandes ciclos biogeoquímicos impidiendo en reciclado de los materiales finitos y alterando las bases reguladoras del clima (p. 24)

Los resultados no pueden ser los mejores más allá de las grandes ganancias que tiene una minoría absoluta de la sociedad, cuyo crecimiento económico son exiguos al ser comparados con los efectos catastróficos generados al presente y futuro de la vida. Los impactos son evidentes en la reducción de las posibilidades de acceder a alimentos y el incremento de alimentos 
sintéticos procesados genéticamente que afectan el periodo de vida del género humano.

Precisamente, el seminario Saberes Ancestrales, Soberanía Alimentaria, realizado el 26 y 27 de septiembre de 2019, insiste en la necesidad de recuperar las prácticas agrícolas en función de la producción de alimentos sanos, fortalecer los procesos etnoeducativos y de educación propia, trabajar por un régimen especial de protección de los saberes alimentarios y saberes ancestrales en general, reglamentar las normas gestionadas por el movimiento social afrocolombiano para sostener las prácticas económicas ambientalmente saludable; lo mismo que enarbolar las banderas de la agenda 2030 para enfrentar los desafíos del cambio climático e impulsar el Observatorio de Saberes Ancestrales para surtir de información sobre su realidad.

El libro, invita a actuar y reflexionar respecto a estas necesidades asociadas a la construcción de democracia desde abajo, es decir, centrada en los derechos colectivos de las comunidades, sus territorios, autonomías y procesos de integración desde las diferencias.

Elaborado a varias voces, pero unidos en el ideario de salvar a las poblaciones afrocolombianas, negras, raizales y palenqueras, y a la sociedad en general, de la hecatombe ambiental en la que, a costa de la naturaleza y el planeta, tiene sumergido la lógica de la acumulación de riqueza material.

En ese orden de ideas, el artículo de Rubén Hernández destaca el debate de la soberanía alimentaria de los pueblos y los impactos de las políticas públicas en la soberanía alimentaria, generando dependencia de capitales ajenos a las realidades de los pueblos y evidenciando pérdida de la identidad y sentido de pertenencia.

El profesor Marrugo, se centra en las prácticas tradicionales agrícolas de la comunidad de Palenque, en la que la etnoeducación es el pilar fundamental para avanzar en la educación de la comunidad, y así fortalecer las manifestaciones culturales que son suyas. Además, plantea el imperativo de construir un enfoque propio de educación, dado que desde la etnoeducación no se ha respondido a la exigencia de la comunidad.

La investigadora Henry, desarrolla su artículo "Kandúmbe: Las prácticas gastro económicas de la mujer palenquera como estrategia de libertad", en la que demuestra que la resiliencia de la mujer palenquera se evidencia por medio de su herramienta fundamental, la ponchera, que garantiza la seguridad alimentaria de las nuevas generaciones, desde el cuerpo de la mujer.

El trabajo etnográfico de Delgado con su texto "Comer en San Basilio de Palenque: Memorias, sabores, saberes en tierras africano-colombianas", 
muestra sus distintos momentos en los que disfrutó los diálogos con muchos nativos de la comunidad, quienes le dejaron un mensaje alrededor del comer en Palenque, y el papel de las tiendas en la preparación de la misma.

Desde La Guajira, Vanegas en su artículo "Cachirra, plato endógeno: Aroma, sazón y sabor de la gastronomía del pueblo negro ancestral del corregimiento de Camarones, Distrito de Riohacha, departamento de La Guajira," en el que visibiliza la tradición de la comida de la cachirra en el plato de los nativos de Camarón, y sus diversos ingredientes para su preparación. Además, de hacer una descripción general del territorio y su ubicación en la costa Caribe.

El investigador Morales, nos conecta con su texto "Legado africano en la cocina del Caribe colombiano", mostrando los diversos alimentos del continente africano que se introdujeron a estas tierras con la trata trasatlántica que vivieron los hombres y mujeres esclavizados. Además de mencionarlos, los ubica en sus regiones de origen.

Por último, Daza y Muñoz, con su investigación "Las complejas tramas gastronómicas que se cantan y se bailan: Un relato en dos tiempos en contextos socioculturales de las africanías del Caribe colombiano", muestra la diversidad cultural de esta región que han denominado Caribe, en la que están presente los diferentes sabores, olores y colores de un país que la música varía.

Finalmente, Gil Gavalo, cierra este texto con un poema de su autoría en 1948 denominado "La ensalada porteña", que recuerda el rico menú caribeño.

Es un texto con estilo agradable, hermosa diagramación y una policromía que invita a su lectura como timonel del quehacer de la población afrocolombiana, negra, raizal y palenquera y el movimiento social que lo representa comprometido con la defensa de los saberes ancestrales, la soberanía alimentaria y la construcción de democracia desde abajo.

\section{Referencias Bibliográficas}

Herrero, Y. (2012). Propuestas ecofeministas para un sistema cargado de deudas. Revista de economía crítica, 13, págs. 30-54 Recuperado de: http://revistaeconomiacritica.org/sites/default/files/revistas/n13/2_REC13_Artic ulo_Y_Herrero.pdf

Zapata Olivella, M. (1983). Changó el gran putas. Bogotá: Educar editores. 